\title{
A community of practice approach to enhancing academic integrity policy translation: a case study
}

\author{
Alison Kay Reedy ${ }^{1 *}$ (D) Penelope A. S. Wurm ${ }^{1}$, Amanda Janssen ${ }^{2}$ and Alison Lockley ${ }^{1}$
}

\author{
* Correspondence: alireedy3@gmail. \\ com \\ ${ }^{1}$ Charles Darwin University, Darwin, \\ Australia \\ Full list of author information is \\ available at the end of the article
}

\begin{abstract}
Introduction: Academic integrity policy that is inaccessible, ambiguous or confusing is likely to result in inconsistent policy enactment. Additionally, policy analysis and development are often undertaken as top down processes requiring passive acceptance by users of policy that has been developed outside the context in which it is enacted. Both these factors can result in poor policy uptake, particularly where policy users are overworked, intellectually critical and capable, not prone to passive acceptance and hold valuable grass roots intelligence about policy enactment.
\end{abstract}

Case description: The case study presented in this paper describes the actions of a community of practice (CoP) at a regional Australian university to deconstruct and translate ambiguous academic integrity policy into a suite of accessible academic integrity resources that were intelligible to staff and students, and which assisted academic staff to consistently enact policy. The paper narrates the formation of the $\mathrm{CoP}$, the tangible and intangible value it created, the social learning practices enacted by its members, its grassroots policy work and the material resources produced from that work.

Discussion and evaluation: An evaluation of the CoP was conducted using a value creation framework to explore its immediate value, potential value, applied value, realised value, and reframing value. These values were considered at each stages of the CoP's lifespan. The evaluation was a useful process that demonstrated the wide-ranging value created by the CoP. Six insights were drawn from the evaluation which promote understanding of the value created for a university by a CoP, particularly in contributing to academic integrity culture over a sustained period of time.

Conclusions: This paper contributes to a research gap on specific examples of discretion within rule-based systems. It illustrates how academics and members of the CoP used their discretion to interpret and enact academic integrity policy within a higher education setting. Drawing from the evaluation of the COP we argue for greater understanding of the grass-roots contribution of academic and professional staff to academic integrity policy translation and enactment.

Keywords: Community of practice, Street-level bureaucrats, Policy translation, Policy enactment, Third space academics, Academic integrity

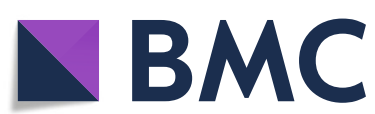

(c) The Author(s). 2021 Open Access This article is licensed under a Creative Commons Attribution 4.0 International License, which permits use, sharing, adaptation, distribution and reproduction in any medium or format, as long as you give appropriate credit to the original author(s) and the source, provide a link to the Creative Commons licence, and indicate if changes were made. The images or other third party material in this article are included in the article's Creative Commons licence, unless indicated otherwise in a credit line to the material. If material is not included in the article's Creative Commons licence and your intended use is not permitted by statutory regulation or exceeds the permitted use, you will need to obtain permission directly from the copyright holder. To view a copy of this licence, visit http://creativecommons.org/licenses/by/4.0/. The Creative Commons Public Domain Dedication waiver (http://creativecommons.org/publicdomain/zero/1.0/) applies to the data made available in this article, unless otherwise stated in a credit line to the data. 


\section{Introduction}

Academic staff are the main interpreters and implementers of academic integrity policy at universities. They are street-level bureaucrats (Lipsky 1971), the "front-line workers... [who] enact public policy [or in this case university policy] in their routine work" (Cooper et al. 2015, p. 376). In the development of the sociological theory of street-level bureaucracy, Lipsky (1971) argues that the exercise of discretion is a dimension of the work of people in public service roles, including educators. This discretion plays out in the implementation of policy, where "pragmatic micro choices ultimately become the de facto policy of the organisation, which may contrast starkly with its official stated aims" (Cooper et al. 2015, p. 376). For academics, constraints such as lack of "time, information, or other resources" (Lipsky 2010, p. xi) influence pragmatic choices made in the enactment of policy. Hence, policy may not be enacted as intended by its architects and may reflect the "unsanctioned work responses" (Lipsky 2010, p. xii) of those people charged with its implementation. Policy is then experienced as the "aggregation of the separate actions of many individuals" (Lipsky 2010 p. xii-xiii) during its enactment, with students directly impacted through inconsistent and inequitable treatment if they are alleged to have breached academic integrity.

The autonomy and discretion of street-level bureaucrats in interpreting and enacting policy is a form of power that is wielded through judgement-based rule-breaking or rule-bending as each case is considered (Portillo and Rudes 2014). The rules relating to academic integrity are set out by higher education institutions in their governance documents, including policy, procedures, codes of practice and other strategic documents (referred to collectively as 'policy' in this paper). In Australia the higher education regulatory body, the Tertiary Education Quality and Standards Agency (TEQSA), establishes the standards that should be reflected by institutional policy and practices. Institutional management makes policy that is intended to comply with the regulatory framework and align with the institutional environment. Academics are then presumed to translate policy into action, with the aim that students experience policy in a consistent manner. This vision of a linear and hierarchical model of the translation of academic integrity policy is articulated by Universities Australia, the peak body representing Australian universities.

Universities are required by a range of legislation and supporting regulations to ensure that academic integrity is upheld as central to educational standards, that its importance and meaning is communicated to students and staff, and that breaches and academic misconduct are pursued in systematic and fair ways (Universities Australia 2017, p. 5).

However, the variability in academic integrity policy enactment across the sector suggests that the hierarchical model of policy translation does not work efficiently or effectively. The academic integrity literature points to a "troubling degree of variability in the way that institutions approach the prevention and remedy of academic dishonesty" (MacLeod and Eaton 2020, p. 11), with this variability evident within and between departments at the same university (MacLeod and Eaton 2020; Morris 2018). The disparity between policy intention and policy enactment is not surprising in education systems, which are also complex "socio-political systems" (Burdett and O'Donnell 2016, 
p. 114), however, this variability has "profound implications" (Lipsky 2010, p. xii) including weakening the institutional culture of academic integrity (MacLeod and Eaton 2020). Not only that, it also diminishes the concept of fairness, as students are subject to different sanctions for academic dishonesty depending on their lecturer and discipline (Morris 2018).

There are many factors that contribute to the variability of approaches, including organisational constraints that "creat[e] a difficult setting for... staff to make consistent and equitable decisions" (Kras et al. 2019, p. 4). One such organisational constraint is when the quality of academic integrity policies and their socialisation does not align with the standards of exemplary academic integrity policy (Bretag et al. 2011). One essential requirement of academic integrity policy is 'access', that is, "policy is easy to locate and read, and is concise and comprehensible" (TEQSA 2017, p. 10), whereas policy documents written in formal and legalistic language can be impenetrable to staff and students. Bretag et al. (2011) point out that if academic integrity policy "is not accessible and understandable to both staff and students, it would be unlikely to be implemented effectively" (p. 6-7). Policy inaccessibility is a particular concern for staff and students from non-English speaking backgrounds and from cultural contexts where academic integrity is understood in different ways to the western academy (Ahmed 2020; Burke and Bristor 2016). Additionally, without support in the form of policy socialisation practices, there is also evidence that academic staff do not access and read academic integrity policy documents until they are confronted with an issue that needs to be dealt with (MacLeod and Eaton 2020).

\section{Case description}

\section{A case study of policy translation by street level bureaucrats}

The case study presented in this paper describes the actions of a community of practice (CoP) (Wenger 1998) at a regional Australian university to deconstruct and translate ambiguous academic integrity policy into a suite of accessible academic integrity resources. The resources were developed to assist academics to consistently enact policy in their practice. The paper narrates the organic formation of the CoP, the tangible and intangible value it created, the social learning practices enacted by its members, its grassroots policy work and the material resources produced from that work. The narrative is then used as the basis of an evaluation of the value created by the CoP (Wenger et al. 2011), for those responsible for policy development within and outside the university, for those enacting policy via their interactions with students, and for students themselves. The authors have chosen language, frameworks and theory in the course of the narrative that help to identify and articulate that value, including the use of Lipsky's (1971) theory of the 'street-level bureaucrat' to describe the role of academic and professional staff in implementing academic integrity policy with students. The authors also use cycles of value creation (Wenger et al. 2011) to identify benefits and impacts created, beyond the material resources themselves. Finally, understandings of the success of the CoP are presented and observations are shared about how academic integrity policy translation can best be achieved.

This paper contributes to a research gap on specific examples of discretion within rule-based systems (Maynard-Moody and Portillo 2010), by illustrating how academics 
and members of the CoP used their discretion to interpret and enact academic integrity policy within a higher education setting. While the resources developed have contributed to an increase in consistency in staff enactment and student understanding of academic integrity policy, there is still a need for whole of university review and redevelopment of academic integrity policy and strategies to support their consistent implementation (Bretag et al. 2011). However, by drawing on the knowledge capital and shared commitment of an academic integrity CoP, its members took agency within their scope of influence rather than waiting for the slower processes of the institutional bureaucracy to act to renew policy.

\section{An academic integrity Community of Practice}

Wenger (1998) defines communities of practice as having three characteristics: a shared 'domain' of interest; a 'community' whereby relationships are built as the members "engage in joint activities and discussions, help each other, and share information" (Wenger-Trayner and Wenger-Trayner 2015, p. 2); and a 'practice' in the field, whereby the members of the community are practitioners who develop "a shared repertoire of resources" (Wenger-Trayner and Wenger-Trayner 2015, p. 2). The CoP discussed in this paper exhibited all of these characteristics.

This CoP comprised of academic and professional staff with a shared 'domain' of interest around the translation of academic integrity policy, who wanted to understand and address why inconsistent application of academic integrity policy was occurring. All members of the community shared a 'practice' that involved some aspect of academic integrity, but from different perspectives and roles in the university. The group formation and composition are addressed later in this paper in the case study narrative section. This small 'community' of committed grass roots-practitioners met regularly from 2014 to early 2021 to deepen their knowledge of academic integrity and the causes of inconsistent enactment of academic integrity policy at the university.

CoPs evolve over time, passing through different stages of growth and development (Wenger et al. 2002). The five stages of development that the academic integrity CoP passed through are shown in Table 1.

Individual members of a CoP have different levels of participation depending on its relevance to them (Wenger et al. 2002). Core members are at the centre of a CoP and

Table 1 Stages of CoP Development (adapted from Wenger et al. 2002)

\begin{tabular}{|c|c|c|}
\hline Stages & Description & Key activities \\
\hline $\begin{array}{l}\text { Stage 1: } \\
\text { Potential }\end{array}$ & $\begin{array}{l}\text { People face similar situations with the benefit of a } \\
\text { shared practice }\end{array}$ & $\begin{array}{l}\text { Finding each other and discovering } \\
\text { commonalities }\end{array}$ \\
\hline $\begin{array}{l}\text { Stage 2: } \\
\text { Coalescing }\end{array}$ & $\begin{array}{l}\text { Members come together and discover their } \\
\text { potential }\end{array}$ & $\begin{array}{l}\text { Exploring connectedness, defining joint } \\
\text { enterprise, negotiating community }\end{array}$ \\
\hline $\begin{array}{l}\text { Stage 3: } \\
\text { Active }\end{array}$ & Members engage in developing a practice & $\begin{array}{l}\text { Engaging in joint activities, creating artifacts, } \\
\text { adapting to changed circumstances, renewing } \\
\text { interest, commitment and relationships }\end{array}$ \\
\hline $\begin{array}{l}\text { Stage 4: } \\
\text { Dispersed }\end{array}$ & $\begin{array}{l}\text { Members no longer engage very intensely but the } \\
\text { community is still alive as a force and a centre of } \\
\text { knowledge }\end{array}$ & $\begin{array}{l}\text { Staying in touch, holding reunions, calling for } \\
\text { advice }\end{array}$ \\
\hline $\begin{array}{l}\text { Stage 5: } \\
\text { Dormant }\end{array}$ & $\begin{array}{l}\text { The community is no longer central but people } \\
\text { still remember it as a significant part of their } \\
\text { identities [and practice] }\end{array}$ & $\begin{array}{l}\text { Telling stories, preserving artifacts, collecting } \\
\text { memorabilia }\end{array}$ \\
\hline
\end{tabular}


coordinate its operations and "move the community along it's learning agenda" (Wenger et al. 2002, p. 56). Active members, occasional participants, peripheral participants and transactional participants have increasingly less engagement in the CoP (Wenger-Trayner and Wenger-Trayner n.d.). In this study we refer to the CoP as encompassing all of these participation levels, however, we focus particularly on the experiences of the core members of the CoP, who initiated its development and coauthored this paper.

In the field of education, Wenger champions communities of practice as opportunities for "peer-to-peer professional-development" (Wenger-Trayner and Wenger-Trayner 2015, p. 5). The academic integrity CoP described in this paper proved to be far more than an opportunity for professional learning and action and continued after completion of the resources. Because of the sense of trust, respect and purpose that developed over time, the members of the $\mathrm{CoP}$ continued to share academic integrity practices, write papers, deliver workshops and conference presentations, and create additional resources. It was through this continued process of learning, theorising and reflection that the CoP came to see itself as a 'third space', which in the context of the academy refers to "the emergent territory between academic and professional domains, which is colonised primarily by less bounded forms of professional" (Whitchurch 2008, p. 377) such as educational developers and academic language academics.

\section{Evaluating the Community of Practice}

As the $\mathrm{CoP}$ was coming to a natural end its core members decided to document the activities of the CoP and the value it created. The tool used to conduct this evaluation was the value creation framework developed by Wenger et al. (2011). Over a period of 6 months from late 2020 to early 2021 the core members of the CoP collectively reflected on the five cycles of the value creation framework: immediate value, potential value, applied value, realised value, and reframing value (Table 2). The core members collected evidence of value creation from a variety of sources including iterations of the resources through their development, records of consultations with staff and students, evidence of conference presentations, unsolicited feedback on the resources and approach taken, public recognition of the resources created and recognition of the expertise of the members of the CoP through invitations to contribute to specialist committees.

The framework of value creation cycles (shown in Table 2) was integrated with the narrative, tracing the stages of the CoP lifespan (see Table 3). Wenger, Trayner and de Laat note that it is through narratives "that one can appreciate what learning is taking place (or not) and what value is created (or not)" (Wenger et al. 2011, p.15). As the CoP core members worked through the reflective process, it became apparent that the value creation cycles and even the stages of the lifespan were intertwined rather than sequential (Table 3). For example, the 'Active' stage of the CoP emerged twice.

\section{Discussion and evaluation}

The following section provides a detailed narrative of the CoP and an evaluation of each chronological stage of its lifespan, from 2014 to 2021, using the value creation framework developed by Wenger et al. (2011). Within this section, the discussion of 
Table 2 Evaluation framework for the analysis of value creation used by the academic integrity community of practice (sourced and adapted from Wenger et al. 2011, p.19-32)

\begin{tabular}{lll}
\hline Cycle & Explanation & Indicators \\
\hline Cycle $\mathbf{1}$ & The activities and interactions & Level of participation; Level \\
Immediate & between members have value & of activity; Level of \\
value: & in and of themselves. & engagement; Quality of \\
Activities and & & interactions; Value of \\
interactions & & participation; Collaboration; \\
& & Reflection.
\end{tabular}

Cycle 2

Potential

value:

Knowledge

capital
The activities and interactions of cycle 1 may not be realised immediately, but rather be saved up as different forms of knowledge capital whose value is in its potential to be realised later.
Cycle 3

Applied value: Changes in practice
Knowledge capital may or may not be put into use. Leveraging that capital requires adapting and applying it to a specific situation and identifying how practice changes.
Human capital: skills acquired, information received, changes in perspective.

Social Capital: Trust, shared understandings, social relationships, inspiration and confidence.

\section{Tangible capital}

Facilitated access to information and resources. Reputational Capital: Recognition of the CoP and academic integrity. Learning Capital: Vison of social learning as valuable; transfer of social learning to other contexts.

Production of tools and documents to inform practice; documentation evidencing changing knowledge; implementation of advice; innovation in practice; use of tools to inform of practice.
Data sources $^{\mathrm{a}}$

Attendance and frequency of meetings; number and characteristics of active members; intensity of discussions; continuity of members; self-reports; evidence of fun; metaconversations about the community.

Self and CoP reflections; retention rates of members; initiatives started and/or risks taken by members; bringing up difficult problems and failures from practice; quantity and types of resources produced (draft and final versions); summaries of events; workshops and feedback from stakeholders (staff and students).
Reflections; iterative and final versions of resources; new ways of doing things; feedback on resources from people who have used them (students and staff); examples of use and reuse; using new knowledge in other contexts e.g. journal articles, committees, other communities of practice.

Views on the website; unsolicited email feedback; feedback from presentations; adoption of the resources; feedback from staff and students on use of resources.
Realised value: Performance improvement
New practices or tools do not necessarily lead to improved performance, so it is important to find out what effects the capital has on the achievement of what matters to stakeholders.

Cycle 5

Reframing value: Redefining success
Social learning causes a reconsideration of the criteria by which success is defined, including a reframing of strategies, goals and values.
Personal performance; organisational performance; Organisational reputation; Knowledge products as performance.

Individual, collective or organisational reframing of success is achieved and measured.
New visions of how academic integrity policy translation can be achieved; different conversations about the causes of inconsistent policy translation.

a The data sources in the table are those used by the CoP in this study

each chronological stages of the $\mathrm{CoP}$ is followed by an evaluation of the value creation in that stage.

CoP stage 1: potential (2014-2015)

In the first stage of the formation of the CoP, 13 academic and professional staff members were brought together by one of the authors in response to a cluster of plagiarism 
Table $\mathbf{3}$ Value created by the CoP across the stages of its lifespan

\begin{tabular}{|c|c|c|c|c|c|}
\hline \multirow{2}{*}{$\begin{array}{l}\text { Stages of the } \\
\text { Academic } \\
\text { Integrity CoP }\end{array}$} & \multicolumn{5}{|c|}{ Cycles of the value creation framework ${ }^{a}$} \\
\hline & $\begin{array}{l}\text { Cycle } 1 \\
\text { Immediate } \\
\text { value: Activities } \\
\text { and interactions }\end{array}$ & $\begin{array}{l}\text { Cycle } 2 \\
\text { Potential } \\
\text { value: } \\
\text { Knowledge } \\
\text { capital }\end{array}$ & $\begin{array}{l}\text { Cycle } 3 \\
\text { Applied value: } \\
\text { Changes in } \\
\text { practice }\end{array}$ & $\begin{array}{l}\text { Cycle } 4 \\
\text { Realised } \\
\text { value: } \\
\text { Performance } \\
\text { improvement }\end{array}$ & $\begin{array}{l}\text { Cycle } 5 \\
\text { Reframing } \\
\text { value: } \\
\text { Redefining } \\
\text { success }\end{array}$ \\
\hline Stage 1: Potential 2014-2015 & $\checkmark$ & $\checkmark$ & $\checkmark$ & & \\
\hline Stage 2: Coalescing 2015-2016 & $\checkmark$ & $\checkmark$ & $\checkmark$ & & \\
\hline Stage 3: Active 2016-2017 & $\checkmark$ & $\checkmark$ & $\checkmark$ & & \\
\hline Stage 4: Dispersed 2018-2019 & $\checkmark$ & $\checkmark$ & $\checkmark$ & $\checkmark$ & \\
\hline $\begin{array}{l}\text { Stage 3: Active (Revisited) } \\
\text { 2020-2021 }\end{array}$ & $\checkmark$ & $\checkmark$ & $\checkmark$ & $\checkmark$ & $\checkmark$ \\
\hline Stage 5: Dormant 2021 & & $\checkmark$ & $\checkmark$ & & $\checkmark$ \\
\hline
\end{tabular}

${ }^{\mathrm{a}}$ Adapted from the value creation framework (Wenger et al. 2011)

${ }^{\mathrm{b}}$ Adapted from the lifecycle of a community (Wenger et al. 2002)

cases in her faculty. The members of the CoP shared a concern about the highly emotional and inconsistent responses by many lecturers to student breaches of academic integrity, and wanted to explore these with like-minded people from across the university who were interested in educating students about academic integrity rather than punishing them. The CoP's initial purpose was to explore ways to support academic staff who were struggling to deal with student breaches of academic integrity and doing so in inconsistent ways. The CoP's concerns included the vulnerability of staff to allegations of unprofessional conduct if their behaviours did not align with the "official stated aims" (Cooper et al. 2015, p. 376) of the university's academic integrity policy.

Through discussions within the $\mathrm{CoP}$ and with other colleagues, a range of factors were identified that contributed to staff members' inconsistent approaches to enacting academic integrity policy. The main factor was confusion about the university policy for addressing breaches of academic integrity. In addition, the process of investigating a breach was time consuming and not well supported by the text-matching or the breach-reporting software used by the university, leading to staff frustration. Consequently, staff weighed up whether they would report breaches of academic integrity, knowing that there were no consequences for them if they did not report breaches but a significant increase of work if they did.

Further, different disciplinary perspectives on how breaches of academic integrity should be dealt with resulted in a patchwork culture of academic integrity (Bretag 2016; Simon 2015). Staff in academic language programs tended to approach breaches of academic integrity from an educative and developmental perspective and were reluctant to report breaches, while colleagues in disciplines such as engineering and accounting took a more punitive approach and were more likely to report breaches. For law lecturers, there was a reluctance to report breaches of academic integrity as these would be noted on the student record and could impact on whether the student, after graduation, could obtain certification to practice law.

Members of the CoP also shared concerns that many of the students they taught or worked with were unclear about what constituted academic integrity and why it was important. Many students were also unaware of the consequences of academic misconduct and of the processes in place if they were alleged to have committed a breach of academic integrity. 
CoP members contributed de-identified case studies of student breaches of academic misconduct for discussion within the group. Most breaches were of a relatively low level and had resulted from students' lack of understanding of the expectations of the academic culture. From the cases of academic misconduct reviewed within the CoP, international students as a cohort were potentially more vulnerable to committing breaches of academic integrity, although the problem definitely was not confined to international students. Most of the breaches discussed were considered by the CoP to be best dealt with via an educative response that included opportunities for students to develop academic writing skills as well as education about the university's academic integrity policy.

$\mathrm{CoP}$ members also shared resources that they had developed or were developing to support student understanding of academic integrity including an online quiz and an academic integrity checklist. With the aim of supporting a culture of academic integrity, the CoP created a 'Student Expectations' document to assist students to understand what actions they needed to take to develop their academic integrity knowledge and skills and avoid plagiarism. This simple document listed the resources and services provided by the university and was made available to all group members to use with their students and to disseminate to colleagues. In one faculty the document was placed on the faculty website for use by students and staff. The Student Expectations document signalled an output and a natural pause for the CoP by mid-2015.

\section{Value creation in stage 1}

In the first stage of its lifespan the CoP created immediate value (Cycle 1 of the value creation framework), potential value (Cycle 2 of the value creation framework) and applied value (Cycle 3 of the value creation framework). The immediate value to the CoP members came from regular meetings, every 2 to 3 weeks, where the members got to know each other and began sharing experiences and examples of how student academic integrity was supported and how breaches were responded to in their disciplines or work units. Through the process of knowledge sharing, the CoP members built different forms of knowledge capital. In particular, the members shared information about policy enactment (human capital) and gained access to resources that had been created by others (tangible capital). As noted by Wenger et al. (2011, p.19-32), potential value in the form of knowledge capital is not necessarily realised or put into use. However, the CoP leveraged knowledge capital to create the 'Student Expectations' document, which then became a much-used document in at least one faculty. That document evidenced the applied value of the CoP.

\section{CoP stage 2: coalescing (2015-2016)}

In the coalescing stage of the $\mathrm{CoP}$ three core members continued to meet, motivated by their developing respect for each other's practice, recognition of the value of their shared learning, and interest in developing further ideas about how to improve academic integrity at the university. The remainder of the inaugural CoP members took on peripheral participation in the community. The core members reflected that the Student Expectations document only targeted student behaviours but did nothing to address the variable ways in which academic staff interpreted and enacted policy, resulting in a gap between policy intention and practice (East 2009). 
The main focus of the CoP in stage 2 of its lifespan was shared in-depth reading of the academic integrity policy. This robust process involved many discussions about the intended meaning of individual words, phrases and sections of the policy. Even after 6 months or so of fortnightly meetings and discussions, the CoP core members still had very different understandings of the policy intent. The consensus reached by the CoP core members was that the policy was ambiguous and needed review and updating. Advice received from the governance area of the university was that there were plans to review the policy but not in the near future.

With the knowledge acquired through taking apart and discussing in detail every aspect of the academic integrity policy, the CoP sought funding to translate this new policy knowledge into resources to help others in the form of flow charts that would make it easy for staff and students to understand. The CoP core members wrote a small internal grant application, which was taken to the whole CoP for input, review and suggestions. The grant was successful and a plan for the creation of a suite of academic integrity resources was hatched.

\section{Value creation in stage 2}

In stage 2 of the CoP's lifespan, the immediate value (Cycle 1 of the value creation framework) of the $\mathrm{CoP}$ was realised through fortnightly meetings of the CoP core members. This stage represented the creation of potential value during this intense period of knowledge acquisition (Cycle 2 of the value creation framework) as the CoP core members unpacked, discussed and debated the intent of the academic integrity policy. Three core members contributed to these robust discussions actively, passionately and respectfully. The discussions led the CoP members to read widely about academic integrity generally, and specifically about the characteristics of good academic integrity policy (Bretag et al. 2011), which then informed learning and subsequent discussions and contributed to human capital development.

These discussions were the starting point for the CoP core members to build shared understandings about academic integrity, and also led to the start of a close professional relationship between them. Over time the trust and confidence between the core CoP members became increasingly important social capital, demonstrated in the core members' commitment to its work.

The development of the grant application and project plan were evidence of the applied value of the CoP (cycle 3 of the value creation framework). The core CoP members leveraged their acquired knowledge about academic integrity and identified the need for resources to be created in the absence of a clear academic integrity policy. The opportunity to apply for an internal grant was the catalyst of what became the academic integrity resource development project, a project conducted by the core $\mathrm{CoP}$ members with clear aims and outputs and the objective of enhancing the university's culture of academic integrity.

\section{CoP stage 3: active (2016-2017)}

The third stage of the CoP's lifespan involved the active creation of academic integrity resources. The CoP core members approached the university's internal design studio to work with it on the visual design and production of two flow charts, given that 
visual representation can enhance cognition (Bingham et al. 2016). The first flow chart was to guide staff through the process of investigating a student breach of academic integrity. The second flow chart was to make visible to students the stages of the investigation process if they were subject to an alleged breach of academic integrity.

Initially the CoP approached the media studio with the idea of creating the flow charts as multi-media branching scenarios in a game-based format. At this time, several staff from the design studio became transactional members of the CoP, with the manager of the design studio becoming a core member of the CoP as the project progressed. The manager recommended that the flow charts be developed as static resources because they would be simple to use, and could be disseminated digitally, hung up around the university and used for multiple purposes.

The core CoP members engaged in further robust discussion as they negotiated the complex processes of translating the academic integrity policy into flow charts. The development of the flow chart prototypes took a year of work and many iterations, as information on the stages of the flowcharts and their design flowed between the core CoP members and the design studio. Three of the many iterations of the flow charts are shown in Fig. 1.

The complexity of the policy resulted in the final staff flow chart extending over three pages while the simplified student version extended over two pages. Colour coding was used in the flow charts to delineate between the roles of students, academic staff, unit coordinators, the complaints management unit, heads of school, pro-vice chancellors, and a board of inquiry. These final versions featured distinctive visual motifs and use of colour.

During the development of the flow charts, the CoP conducted comprehensive consultation with the end users, both Vocational Education and Training (VET) and Higher Education (HE) academics, as well as with other members of the university community. Consultation was via workshops which focussed on testing drafts of the

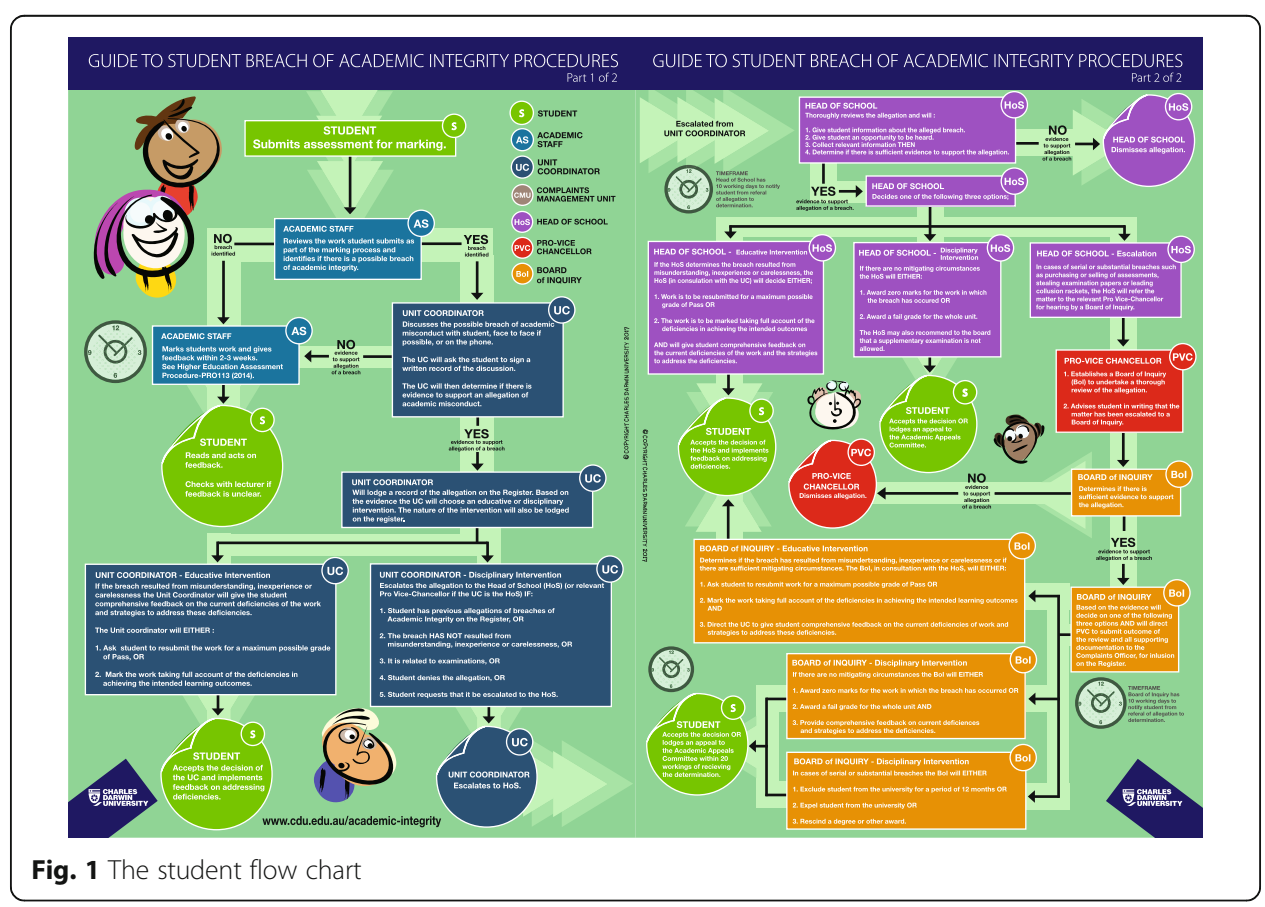


flow charts with small groups. A small workshop for students was also held. Detailed feedback was collected immediately, in-person and in writing on the drafts provided to workshop participants. The feedback received then fed into their iterative development between workshop, as the CoP members' understandings of the policy and how it could be presented most clearly were refined. Five workshops were held in three national jurisdictions during which 65 staff members provided sense checking of the flow charts against their street-level interpretation and enactment of policy. The workshops stimulated conversations about consistency and equity in the enactment of policy as they simultaneously revealed accounts of discretionary decision making. The workshop

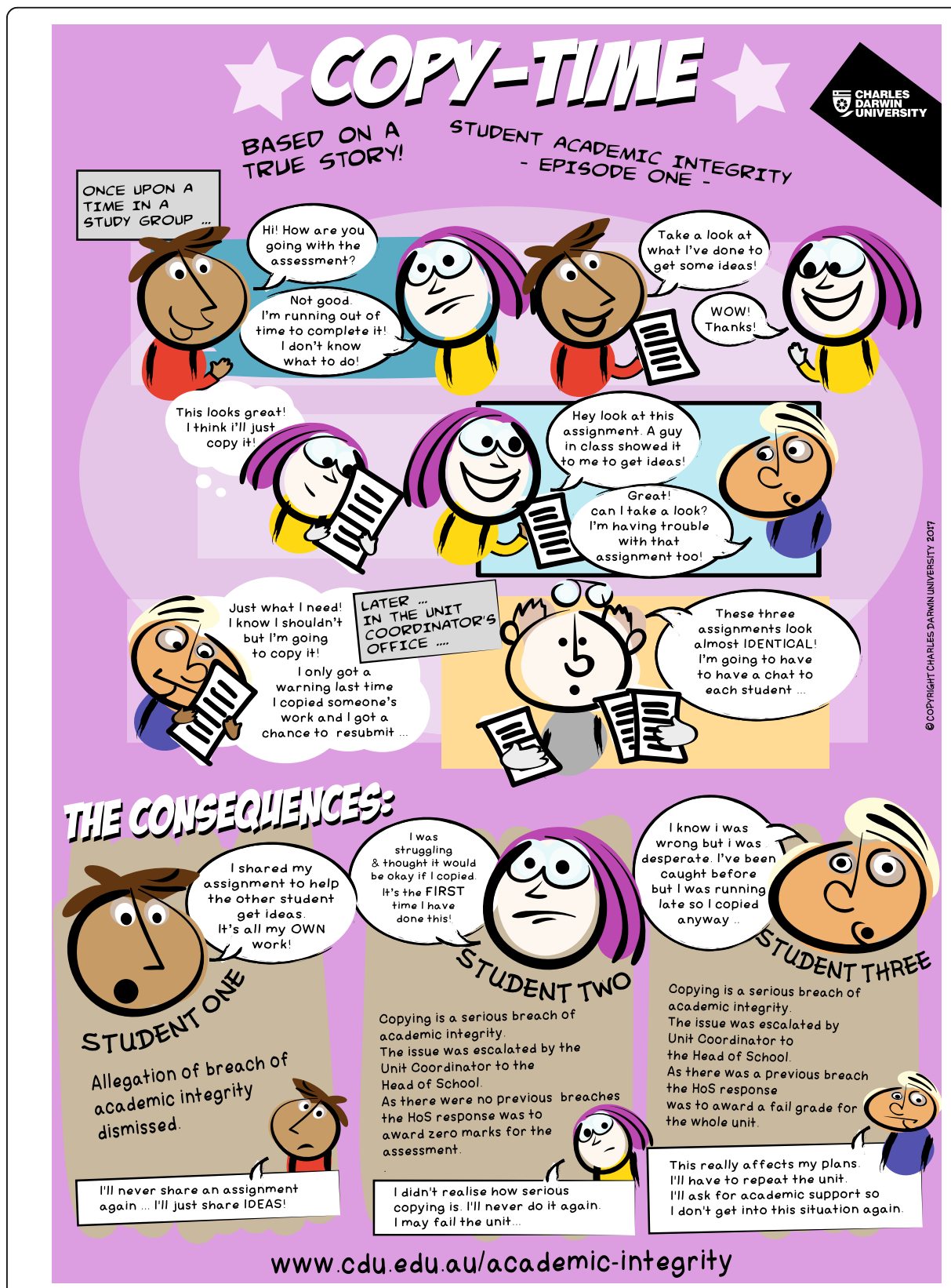

Fig. 2 One of the comic strip scenarios of academic integrity breaches that occurred at the university 
discussions were de facto professional learning sessions and a starting point for socialisation of academic integrity policy across the university.

The workshops contrasted with the university approach to the socialisation of policy, whereby policy is conveyed to staff by an email requesting that they register their acceptance of university governing documents by logging on, opening and accepting each new policy document. By opening the document, it is assumed that the policy has been read and understood. The language used in the communication emphasises risk mitigation and assigns staff to passive roles of awareness and compliance. This method of policy socialisation contrasts with the normal roles of academic work which involve exercising critical skills and discretion.

In addition to the flow charts, the CoP developed five scenarios of academic misconduct and its consequences. These were created in comic strip format (Fig. 2) and covered topics such as plagiarism (The Write Way), copying other students work (Copy-Time), contract cheating (The Ghost Who Writes), collusion (The Collusion Caper), and synonym scrambling (The Synonym Twist). The scenarios were based on actual breach events at the university that precipitated the project and provided tangible examples of decisions made by students that lead to breaches of academic integrity. The scenarios showed the range of consequences when breaches occur, from educational responses for minor breaches through to exclusion from the university.

Cartoon characters were chosen to provide creative and distinctive theming and visual motifs that linked the scenarios and flow charts (Benson et al. 2019). They also provided an engaging, visual way to convey an important message while avoiding stereotyping of students or staff or trivialising the issue. To ensure accessibility, maximise engagement and transfer of information, strategies such as streamlining and chunking of information and conversational language were used (Rudolph 2017). These strategies removed the ambiguity that existed in the policy documents and made the academic integrity content more easily recognised and remembered (Bingham et al. 2016; Short et al. 2013).

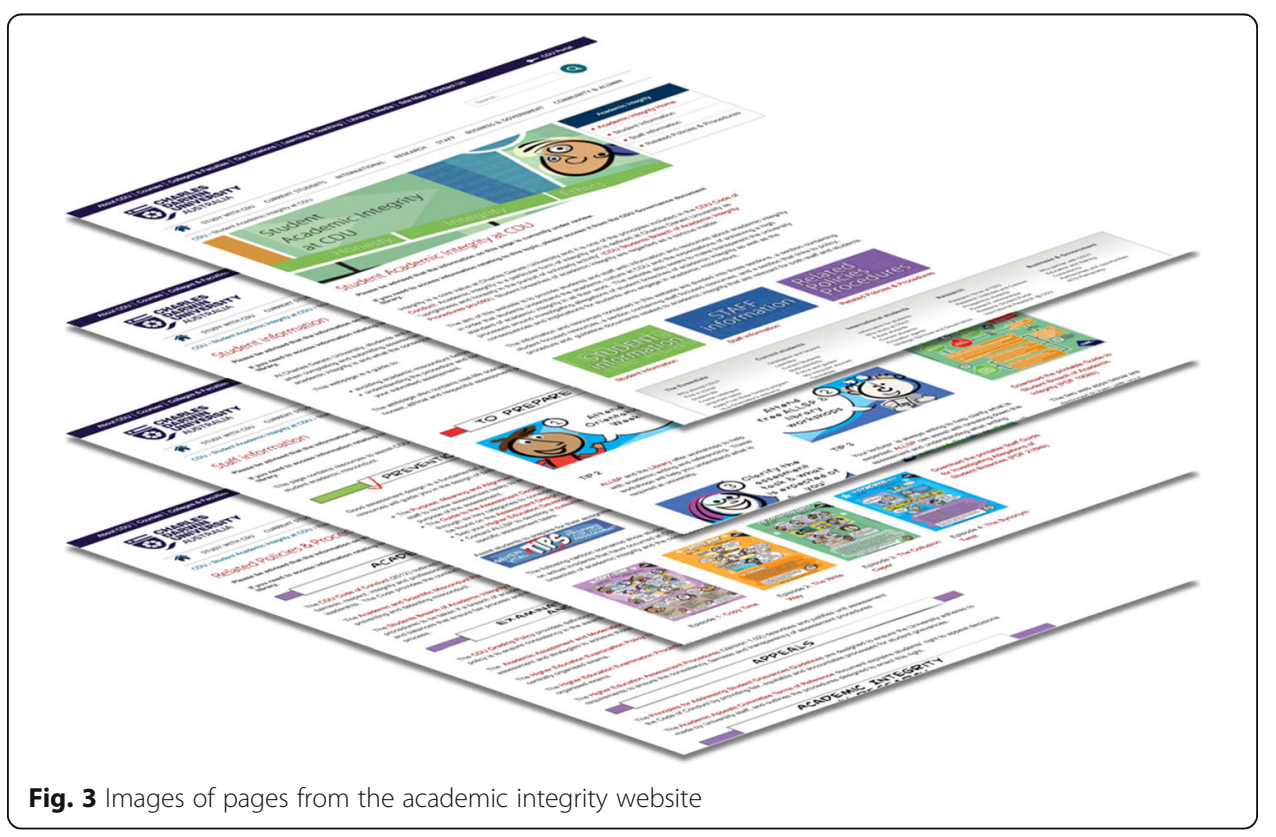


All the resources were shared through a website (Fig. 3) which provided students and staff with timely and readily accessible information about academic integrity, connected students with support, put into perspective the consequences of academic misconduct, and linked to additional resources. Students and staff who reviewed the flow charts before their release positively endorsed them, with one student remarking that it was a relief to see the university wide process in place to protect staff and students.

The resources were finished in 2016 and were rolled out in 2017 through formal channels such as student orientation sessions, staff workshops and new staff orientation. The CoP core members were active in delivering workshops to faculties across the university to familiarise staff with the academic integrity resources and to provide suggestions for their use.

\section{Value creation in stage 3}

The resource development stage of the project was the most active period in the lifespan of the CoP. The core members continued to meet fortnightly to break down the policy into steps that would be converted into the flow charts. They also consulted with staff and students about the ease of understanding the flow charts. The consultations resulted in socialisation of the academic integrity policy, with the final suite of resources assisting with its ongoing socialisation.

There were also meetings with the design studio to explore the resource design options (Cycle 1 of the value creation framework). The meetings of the core members of the CoP continued to be intense, and the design of the flowcharts also brought the peripheral and transactional members of the CoP (design studio) into the discussion, increasing the knowledge base about academic integrity policy across the university (Cycle 2 of the value creation framework - building human capital). The creation of the resources also reflected the tangible value of the $\mathrm{CoP}$ and evidenced the applied value of the $\mathrm{CoP}$ in relation to academic integrity (Cycle 3 of the value creation framework).

\section{CoP stage 4: dispersed (2018-2019)}

The energy and commitment of the members of the CoP was sustained for a six-year period, with meetings becoming less frequent in 2018, once the resources had been launched and socialised. In 2018 and 2019 the core CoP members dispersed, only meeting on an as-needs basis. This stage in the lifespan of the CoP was characterised by the dissemination and use of the resources.

Academics' use of the resources contributed to an increase in consistency in staff enactment of academic integrity policy and in student understanding of it. Personal communications to the core CoP members recounted use of the flow charts and scenarios

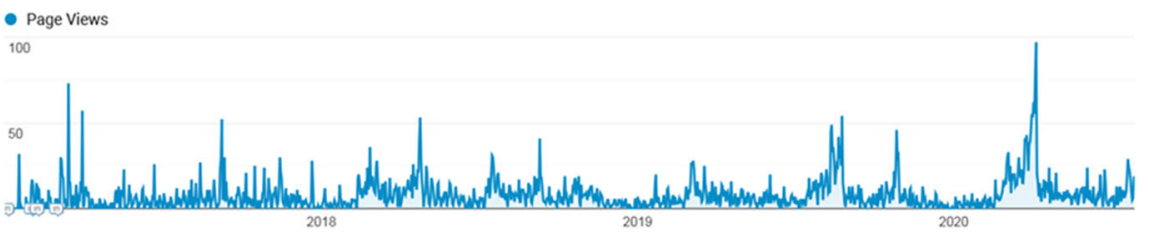

Fig. 4 Student Academic Integrity at CDU Website page views 2017-2020 
for counselling students regarding detected breaches, and integration of them with assignment instructions.

The scenarios were also well used, with feedback received that they helped students understand concepts like plagiarism that had previously been difficult for students to relate to. The scenarios were "like a light bulb going on" (pers comm 21/9/20), with staff reports of students they had used the resources with taking more care with their writing, with reduced incidences of plagiarism in those courses.

Staff members also used the resources to support students before and during semester and as an educative approach to academic breaches, to explain expectations, for use before assessment submission, and if there was a suspicion of an academic integrity breach.

The resources were used widely across the university, in the academic language and learning program and in orientation sessions for new academic staff. Peer Assisted Study Session (PASS) leaders also used the resources to inform study groups about academic integrity.

At the institutional level, the resources were recognised by management as valuable, and a link to them was put into every higher education unit in the university's learning management system ( $n=778$ units in 2017). Their visibility was enhanced with printed posters of the flow charts and scenarios placed in prominent locations around the university campuses.

The website also increased the visibility of the resources inside and outside of the university. Between 2017 and mid-2020 the site analytics (Google analytics) showed that over 10,000 people accessed the website (Fig. 4), with views from at least 23 Australian universities as well as from overseas universities and from Australian and overseas government departments. Unsolicited emails were received from academics at Australian and New Zealand universities asking permission to adapt the resources for their own use.

Core CoP members were recognised and invited to contribute to academic integrity advisory boards in 2017, 2018 and 2020. Dissemination of the resources outside of the university also took place through conference presentations (Janssen 2017; Janssen et al. 2017; Reedy et al. 2017), which resulted in external recognition, including from Professor Tracey Bretag, an internationally recognised academic integrity expert. Professor Bretag wrote that the resources were "truly excellent" (pers comm 13/11/ 2017) and commented on their ease of access for students and staff and on the design qualities, including noting that "the cute little cartoon characters work really well as a recurring motif!" (pers comm 13/11/2017).

\section{Value creation in stage 4}

Four of the value creation cycles were visible in this stage of the CoPs lifespan. Although meetings were infrequent, the CoP members met to deal with issues such as updating the website, preparing conference presentations and for the socialisation of the resources (Cycle 1 -immediate value). The resources made the work of the CoP visible to university management, university staff, and outside of the university. This visibility enhanced the reputation of the CoP members and resulted in invitations to sit on academic integrity working groups (Cycle 2 - potential value). The dissemination and wide use of the resources was evidence of the applied value of the knowledge created (Cycle 3) while the realised value of the resources was evident in changed 
practices of some academics and students in relation to academic integrity (Cycle 4). The external recognition of the resources created realised value for the university in terms of organisational reputation.

\section{CoP stage 3 revisited: active (2020-2021)}

Just as the CoP was starting to wind down a series of opportunities emerged that motivated the four core $\mathrm{CoP}$ members to start meeting actively again. First, the national university regulator, the Tertiary Education Quality and Standards Agency (TEQSA), invited the CoP to submit case studies of the suite of resources to be profiled in the TEQSA Academic Integrity Toolkit (TEQSA 2020). The CoP met and wrote three case studies which each highlighted a different aspect of the academic integrity resources: academic integrity breach decision making; making academic integrity visible; and academic integrity education (Reedy et al. 2020; Reedy et al. 2020a, b). The TEQSA website states that the case studies in the Toolkit "support Australian higher education providers to meet the academic integrity requirements detailed in the Higher Education Standards Framework" (TEQSA 2020).

Second, the CoP core members submitted a nomination for the 2020 Australian Awards for University Teaching (AAUT). The CoP core members met weekly over several months to prepare the nomination, which won a 2020 citation for developing innovative resources that make visible and clearly communicate the university's procedures and expectations around student academic integrity to the university community. This citation recognised "the impact that the work had [on the university] and the broader HE sector in Australia" (pers comm, chair of the Citation Awards Committee, 15 Feb 2021).

Third, the university went through a significant restructure and the positions of three of the four CoP core members were made redundant. This stimulated the four core CoP members to reflect on the sense of community that had been created by the CoP, the value of its work and the importance of the knowledge that had been generated by it.

The core CoP members met frequently over 6 months to document the trajectory of the $\mathrm{CoP}$ and to evaluate the $\mathrm{CoP}$ (as opposed to just the resources created by the CoP). These meetings, both before and after the redundancies came into effect, reinforced the value of the CoP as a location of rich learning that had led to the development of strong and productive professional bonds (social capital) and the provision of mutual ongoing support. In these meetings the conversations turned towards theorising the learnings and experiences. The core members engaged with the concept of "third space" (Veles et al. 2017; Whitchurch 2008) to explain the importance of shared academic and profession relationships in spaces such as CoPs that provide a sense of trust, respect and identity, across discipline and departmental boundaries within an organisation, particularly where these are not manifest in other parts of the professional landscape. The concept of the "street-level bureaucrat" (Lipsky 1971) was explored which enhanced the core CoP members' understanding of the reasons for the mismatch between policy intent and policy enactment. The CoP core members also explored the meta-level outcomes of a CoP, and particularly the value of social learning and its potential for informing and sharing policy (Wenger 1998). 


\section{Value creation in stage 3 (revisited)}

This stage of the CoP lifespan was one of reflection and introspection that also generated new knowledge as the core $\mathrm{CoP}$ members theorised their experiences and evaluated the CoP using the value creation framework developed by Wenger et al. (2011). It was evident that value was created by the CoP across all of the value creation cycles during this final burst of activity.

In order to collectively reflect and write, the core CoP members held regular meetings during which there was a high level of interaction and engagement (Cycle 1 of the value creation framework - immediate value). The CoP core members explored theoretical concepts to help them make sense of the experiences and knowledge generated through the $\mathrm{CoP}$ which generated new learning (Cycle 2 of the value creation framework - potential value). That is, individual knowledge (human capital) continued to be built, and the CoP members explicitly discussed the value of social learning that had been generated by the CoP and transferred to other projects (learning capital). These meetings also drew on the trust and strength that had been built between the members to provide mutual support during the restructure of the university (social capital) and resulted in institutional and national recognition to the CoP core members (reputational capital). The applied value (Cycle 3 of the value creation framework - applied value) was evident in the tangible products of the CoP created during this stage of its lifespan: case studies; nomination documentation and a written recollection and evaluation of the CoP. These provided evidence of the impact of the resources inside and outside of the university which had a positive benefit on the university's reputation (Cycle 4 of the value creation framework - realised value).

The discussions and theorising led the CoP core members to reflect on the value of the $\mathrm{CoP}$ as much more than a mechanism for creating academic integrity resources (Cycle 5 of the value creation framework - reframing value).

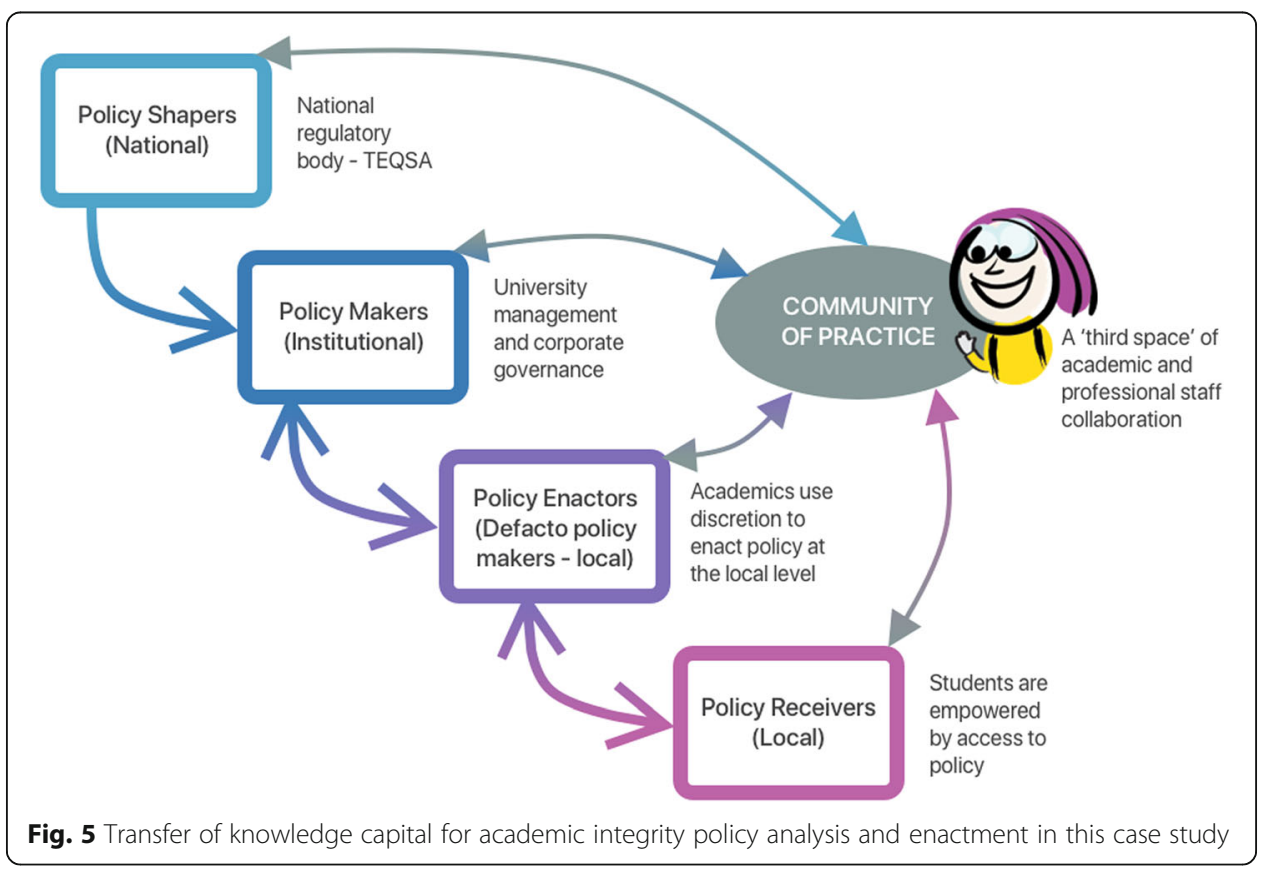


CoP stage 5: dormant (2021)

The life of the CoP finished in early 2021 when the final burst of activity of the CoP (Stage 3 revisited) was completed. As the CoP was winding down, the core CoP members continued to reflect on the activities of the $\mathrm{CoP}$ and what involvement in the $\mathrm{CoP}$ had meant to each of them. The professional and social capital built through the shared learning and work of the CoP and the creation of academic integrity resources had led to the $\mathrm{CoP}$ becoming a creative, trusted, multi-disciplinary and generative space where the members had a sense of collective belonging and shared identity as academic integrity experts. This 'third space' transcended the false dichotomy of the roles of professionals and academics in the institution and legitimised the work done together. It also reflected the "shifting job roles and identities of both professional and academic staff in the contemporary global university environment... that transcend traditional academic and professional portfolio binaries" (Veles et al. 2017, p. 1).

While reflecting on the process of analysing and translating policy, the concept of the street-level bureaucrat (Lipsky 1971) emerged and disrupted the presumption that hierarchical approaches to policy lead to enactment of policy as intended. Instead, the CoP recognised its role in changing the communication flows around academic integrity policy at the university, from uni-directional to multi-directional (Fig. 5).

The members of the CoP exercised critical skills and discretion as street level bureaucrats in developing the resources, and in doing so lifted themselves and other staff from passive acceptance of ambiguous and unintelligible policy to proactive and informed policy makers at the local level. The CoP also informed the policy shaper (TEQSA) and contributed to shaping the policy environment through inclusion of case studies developed by the CoP in TEQSA's Academic Integrity Toolkit (2020). That is, the resources generated to address problems with the accessibility of institutional policy were used as exemplars of good practice by the national regulating body.

The CoP also stimulated a two-way communication pathway between the university management and the CoP. The CoP identified an issue with the way policy was written that impeded its consistent interpretation and enactment. CoP members became policy-interpreters, mediating the space between the official policy makers and academics through the resources and their socialisation and use. The resources were sanctioned by the university through their integration into the online learning environment, the promotion of the resources in the university website, as demonstrations of regulatory compliance with TEQSA standards, and through their use by many academic staff and students. The CoP used the knowledge capital gained in the production of the resources to provide management with recommendations for enhancements to the academic integrity policy to make it more accessible and comprehensible.

The CoP came to recognise its members and other academics and professional staff as street-level bureaucrats who adopted coping mechanisms and applied discretionary decision making to inform the enactment of policy within the constraints of their work at the front line with students by "solv[ing] conflicts or bridg[ing] gaps between policymaking and practical work" (Virtanen et al. 2018, p. 724). That is, the CoP and other academics and professional staff used discretionary power to enact policy within certain parameters through which de facto policy was created. The flow charts and scenarios also provided students with knowledge about policy and tools to actively challenge its enactment when this was inconsistent or unclear (Cornwall and Gaventa 2000). 


\section{Value creation in stage 5}

As the CoP wound up, the social capital it created (Cycle 2 of the value creation framework - potential value) was reinforced as the core members reflected on the activities of the CoP (Cycle 5 of the Value Creation Framework - reframing value). These reflections are captured in the conclusion section of the paper. The value of the CoP lives on in multiple ways, including through the resources and their continued use (Cycle 3 of the Value Creation Framework - applied value), and in the creation of new CoPs by the members of the academic integrity CoP.

\section{Conclusions}

The core members reflected on their key learnings from their involvement in the CoP, during the final stage of its lifespan. Following are six insights aimed at promoting understanding of the value created for a university by a community of practice, particularly in contributing to academic integrity culture over a sustained period of time.

First, the critical work of policy development starts with problem framing. It is inadequate to remove problem and policy framing from the site of its enactment and then expect it to trickle down. The expertise and knowledge capital of academics and professional staff is currently an underutilised resource in problem framing. The expertise of street-level bureaucrats should be utilised prior to policy being written to ensure that the problem to be addressed through policy has been defined through multiple perspectives and not just through the managerial lens. A community of practice can play a role in achieving this.

Second, a hierarchical form of institutional management is likely to miss out on knowledge capital and street level intelligence - held by both staff and students. This is exacerbated when policy development occurs far from the site of use by the street-level bureaucrats who engage in the discretionary enactment of policy and from the students who are impacted by it. To counter this, street-level bureaucrats need to be involved in the co-creation of academic integrity policy. A community of practice can play a role in achieving this.

Third, when the resource development project described in this paper took place there were pockets of individuals and groups in different areas of the institution acting independently to fill gaps in the academic integrity policy and culture. For example, an academic integrity quiz for students was created by library staff. The context of these ad hoc actions, including the work of the CoP, was the absence of a holistic or strategic institutional approach to academic integrity. A university level strategy should encourage these kinds of street-level actions within a framework where these actions are evaluated, endorsed, connected and disseminated.

Fourth, the socialisation of policy is critical to its consistent enactment. The embedding of policy analysis in the practices of the university community is an effective means of socialising policy. In this case the CoP core members became experts in academic policy by engaging actively with it, and the CoP analysed and engaged others in its translation. That is, the process of policy analysis can be used as a capacity building and policy socialisation tool.

Fifth, CoPs have inherent value in and of themselves and lead to the formation of knowledge capital that can be realised in different ways across a university. CoPs are important sites for the capture of critical street-level intelligence to inform policy co- 
development as well as sites of creativity for the interpretation and translation of policy into action. Providing explicit encouragement and support for staff to build communities of practice to investigate problems related to teaching and learning practice is likely to have wide ranging benefits for the individuals involved and the institution.

Finally, the small financial investment made by the university to the CoP, combined with the time and commitment of the academic integrity community of practice created significant benefit and had an impact on the wider university community. The value created by the CoP could be viewed as a worthwhile return on investment by the university.

The final observations of the CoP core members reflect the need for street-level input into academic integrity policy development and better socialisation of policy. This may require university management to place greater value and trust in its street-level bureaucrats as integral to a strategic and holistic institutional approach to policy development and the hoped-for consistency of policy enactment.

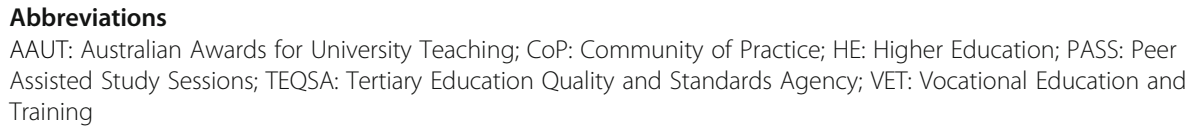

\section{Acknowledgements}

We would like to acknowledge the contribution of peripheral and transactional members of the academic integrity CoP: Dr. Natalie Rossiter-Rachor, Dr. Erica Garcia, George Lambrinidis, Marianne St Clair, Simona Cavani, Brett Smith, Drew Harper, Vibeke Foss, Barbara White, Bernadette Royal, Helen Rysavy and Dan Hartney.

We gratefully acknowledge the graphic design work of Helen Rysavy and Dan Hartney for the conceptualisation and development of the flow charts and scenarios discussed in this paper, and to Helen for her graphic work in this paper. We also acknowledge Dr. Bopelo Boitshwarelo for valuable feedback on early versions of the manuscript.

\section{Authors' contributions}

All four authors met regularly during the writing process to jointly conceptualise the intention of the paper and to plan and review each section. All four authors contributed to the theoretical framing of the paper. The first author led the writing, with sections of text contributed by the other authors. All authors were involved in review, feedback and editing. The author(s) read and approved the final manuscript.

\section{Funding}

We gratefully acknowledge an internal grant of $\$ 11,000$ that was used for the creation of the materials described in this paper.

\section{Availability of data and materials}

The resources described in this paper can be accessed from the following website: https://www.cdu.edu.au/academicintegrity.

\section{Declaration}

Competing interests

The authors declare that they have no competing interests.

\section{Author details}

${ }^{1}$ Charles Darwin University, Darwin, Australia. ${ }^{2}$ University of South Australia, Adelaide, Australia.

Received: 24 January 2021 Accepted: 13 May 2021

Published online: 15 June 2021

\section{References}

Ahmed K (2020) Academic integrity: challenges and strategies for Asia and the Middle East. Account Res 27(5):256-270. https://doi.org/10.1080/08989621.2019.1646646

Benson L, Rodier K, Enstroem R, Bocatto E (2019) Developing a university-wide academic integrity E-learning tutorial: a Canadian case. Int J Educ Integ 15(5):1-23. https://doi.org/10.1007/s40979-019-0045-1

Bingham T, Reid S, Ivanovic V (2016) Paint me a picture: translating academic integrity policies and regulations into visual content for an online course. Int J Educ Integ 12(2):1-13. https://doi.org/10.1007/s40979-016-0008-8

Bretag T (2016) Discipline-specific approaches to academic integrity: introduction. In: Bretag T (ed) Handbook of academic integrity. Springer, Singapore, pp 673-675. https://doi.org/10.1007/978-981-287-098-8_78

Bretag T, Mahmud S, Wallace M, Walker R, James C, Green M, East J, McGowan U, Partridge L (2011) Core elements of exemplary academic integrity policy in Australian higher education. Int J Educ Integ 7(2):3-12. https://doi.org/10.21913/IJEl.v7i2.759 
Burdett N, O'Donnell S (2016) Lost in translation? The challenges of educational policy borrowing. Educ Res 58(2):113-120. https://doi.org/10.1080/00131881.2016.1168678

Burke MM, Bristor J (2016) Academic integrity policies: has your institution implemented an effective policy? Account Educ J Special Edition 2016:1-10 http://www.aejournal.com/ojs/index.php/aej/article/view/338

Cooper MJF, Sornalingam S, O'Donnell C (2015) Street-level bureaucracy: an underused theoretical model for general practice? Br J Gen Pract 65(636):376-377. https://doi.org/10.3399/bjgp15X685921

Cornwall A, Gaventa I (2000) From users and choosers to makers and shapers. Repositioning participation in social policy. IDS Bull 31(4):50-62. https://doi.org/10.1111/j.1759-5436.2000.mp31004006.x

East J (2009) Aligning policy and practice: an approach to integrating academic integrity. J Acad Lang Learn 3(1):A38-A51 https://journal.aall.org.au/index.php/jall/article/view/66/62

Janssen A (2017) From diagnosis to cure? Exploring a reflective partnership to improve university wide knowledge on academic misconduct. In: Presentation at the 13th biennial conference of the Association for Academic Language and Learning: 21st century language and learning, Geelong, Australia

Janssen A, Reedy A, Wurm P (2017) Deciphering academic integrity governance documents: creating equity in diversity by building a culture of academic integrity through accessible resources. In: Presentation at 8th Asia Pacific conference on educational integrity, Sydney University, 6-7 Nov https://8apcei-conference.sydney.edu.au/wp-content/uploads/2017/10/a pcei-conference-program-2017.pdf

Kras KR, Magnuson S, Portillo S, Taxman FS (2019) Tempered radicals: considering street-level community corrections officers and supervisors' divergence from policies. Justice Q. https://doi.org/10.1080/07418825.2019.1639789

Lipsky M (1971) Street-level bureaucracy and the analysis of urban reform. Urban Aff Rev 6:391-409. https://doi.org/10.1177/1 07808747100600401

Lipsky M (2010) Street-level bureaucracy, 30th Ann. Ed.: dilemmas of the individual in public service. Russell Sage Foundation, New York

MacLeod PD, Eaton SE (2020) The paradox of faculty attitudes toward student violations of academic integrity. J Acad Ethics 18:347-362. https://doi.org/10.1007/s10805-020-09363-4

Maynard-Moody S, Portillo S (2010) Street-level bureaucracy theory. In: Durant R (ed) The Oxford handbook of American bureaucracy. https://doi.org/10.1093/oxfordhb/9780199238958.003.0011

Morris EJ (2018) Academic integrity matters: five considerations for addressing contract cheating. Int J Educ Integr 14(15):112. https://doi.org/10.1007/s40979-018-0038-5

Portillo S, Rudes DS (2014) Construction of justice at the street level. Annu Rev Law Soc Sci 10(1):321-334. https://doi.org/1 0.1146/annurev-lawsocsci-102612-134046

Reedy A, Janssen A, Lockley A, Rysavy H, Wurm P (2020) We can see clearly now: making academic integrity visible through an eye-catching website https://www.tegsa.gov.au/sites/default/files/cdu-making-academic-integrity-visible.pdf?v=1588829561

Reedy A, Janssen A, Lockley A, Wurm P (2020a) Going with the flow(chart) makes decision-making easier https://www.teqsa. gov.au/sites/default/files/cdu-going-with-flowchart-makes-decision-making-

Reedy A, Janssen A, Lockley A, Wurm P (2020b) Reimagining educational approaches to academic integrity https://www. teqsa.gov.au/sites/default/files/cdu-reimagining-educational-approaches.pdf?v=1588829573

Reedy A, Wurm P, Janssen A (2017) Untangling the literacies of university governance documents: a community of practice approach. In: Presentation at Australian council for adult literacy conference, traders, neighbours and intruders: points of contact, Darwin, 13-14 Sept http://www.acal.edu.au/conference/full-program/

Rudolph M (2017) Cognitive theory of multimedia learning. J Online Higher Educ 1(2):1-15 http://ojs.iucdt.com/index.php/ johe/article/view/11

Short JC, Randolph-Seng B, McKenny AF (2013) Graphic presentation an empirical examination of the graphic novel approach to communicate business concepts. Bus Prof Commun Q 76(3):273-303. https:/doi.org/10.1177/1080569913482574

Simon (2015) Academic integrity in non-text based disciplines. In: Bretag T (ed) Handbook of academic integrity. Springer, Singapore. https://doi.org/10.1007/978-981-287-079-7_61-1

TEQSA (2017) Good practice note: addressing contract cheating to safeguard academic integrity. https:/www.tegsa.gov.au/ sites/default/files/good-practice-note-addressing-contract-cheating.pdf?v=1507082628

TEQSA (2020) Academic integrity toolkit https:/www.tegsa.gov.au/academic-integrity-toolkit

Universities Australia (2017) UA academic integrity best practice principles https://www.universitiesaustralia.edu.au/wpcontent/uploads/2019/06/UA-Academic-Integrity-Best-Practice-Principles.pdf

Veles N, Boon H, Carter M (2017) The university third space phenomenon: investigating perceptions of professional staff working across boundaries in an Australian university and its Singapore campus. At the Australian Association for Research in Education (AARE) conference 2017. Canberra, ACT, pp 1-3 https://researchonline.jcu.edu.au/52375/1/52375_ Veles\%20et\%20al_2017_abstract\%20only.pdf

Virtanen P, Laitinen I, Stenvall J (2018) Street-level bureaucrats as strategy shapers in social and health service delivery: empirical evidence from six countries. Int Soc Work 61(5):724-737. https://doi.org/10.1177/0020872816660602

Wenger E (1998) Communities of practice. Learning, meaning \& identity. Cambridge University Press, New York

Wenger E, McDermott R, Snyder W (2002) Cultivating communities of practice: a guide to managing knowledge. Harvard Business School Press, Boston

Wenger E, Trayner B, de Laat M (2011) Promoting and assessing value creation in communities and networks: a conceptual framework. Rapport 18, Ruud de Moor Centrum, Open University of the Netherlands https://wenger-trayner.com/ resources/publications/evaluation-framework/

Wenger-Trayner E, Wenger-Trayner B (2015) Communities of practice. A brief introduction. https://scholarsbank.uoregon.edu/ xmlui/bitstream/handle/1794/11736/A\%20brief\%20introduction\%20to\%20CoP.pdf

Wenger-Trayner E, Wenger-Trayner B (n.d.) Levels of participation. https://wenger-trayner.com/project/levels-of-participation/

Whitchurch C (2008) Shifting identities and blurring boundaries: the emergence of third space professionals in UK higher education. High Educ Q 62(4):377-396. https://doi.org/10.1111/j.1468-2273.2008.00387.x

\section{Publisher's Note}

Springer Nature remains neutral with regard to jurisdictional claims in published maps and institutional affiliations. 